\title{
Author Correction: Mechanism-based tuning of insect 3,4-dihydroxyphenylacetaldehyde synthase for synthetic bioproduction of benzylisoquinoline alkaloids
}

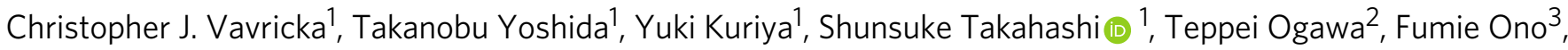
Kazuko Agari ${ }^{1}$, Hiromasa Kiyota ${ }^{4}$, Jianyong $\mathrm{Li}^{5}$, Jun Ishii (i) ${ }^{1}$, Kenji Tsuge ${ }^{1}$, Hiromichi Minami ${ }^{6}$, Michihiro Araki ${ }^{1,3}$, Tomohisa Hasunuma ${ }^{1,7}$ \& Akihiko Kondo (1) ${ }^{1,7,8}$

Correction to: Nature Communications https://doi.org/10.1038/s41467-019-09610-2, published online 01 May 2019.

In the original version of this Article, the abbreviation of 3,4-dihydroxyphenylacetaldehyde synthase presented in the first paragraph of the Discussion section was given incorrectly as DYPAA. The correct abbreviation for this enzyme is DHPAAS. This error has been corrected in both the PDF and HTML versions of the Article.

Published online: 22 May 2019

\begin{abstract}
cc) reproduction in any medium or format, as long as you give appropriate credit to the original author(s) and the source, provide a link to the Creative Commons license, and indicate if changes were made. The images or other third party material in this article are included in the article's Creative Commons license, unless indicated otherwise in a credit line to the material. If material is not included in the article's Creative Commons license and your intended use is not permitted by statutory regulation or exceeds the permitted use, you will need to obtain permission directly from the copyright holder. To view a copy of this license, visit http://creativecommons.org/licenses/by/4.0/.
\end{abstract}

(c) The Author(s) 2019

\footnotetext{
${ }^{1}$ Graduate School of Science, Technology and Innovation, Kobe University, 1-1 Rokkodai-cho, Nada-ku, Kobe 657-8501, Japan. ${ }^{2}$ Mitsui Knowledge Industry Co., Ltd. (MKI), 2-3-33 Nakanoshima, Kita-ku, Osaka 530-0005, Japan. ${ }^{3}$ Graduate School of Medicine, Kyoto University, Yoshida-Konoe-cho, Sakyo-ku, Kyoto 606-8501, Japan. ${ }^{4}$ Graduate School of Environmental and Life Science, Okayama University, 1-1-1, Tsushima-Naka, Kita-ku, Okayama 700-8530, Japan. ${ }^{5}$ Department of Biochemistry, Virginia Polytechnic and State University, 111 Engel Hall, Mail Code: 0308, Blacksburg, VA 24061, USA. ${ }^{6}$ Research Institute for Bioresources and Biotechnology, Ishikawa Prefectural University, 1-308, Suematsu, Nonoichi-shi, Ishikawa-ken 921-8836, Japan. ${ }^{7}$ Engineering Biology Research Center, Kobe University, 1-1 Rokkodai-cho, Nada-ku, Kobe 657-8501, Japan. ${ }^{8}$ Department of Chemical Science and Engineering, Graduate School of Engineering, 1-1 Rokkodai-cho, Nada-ku, Kobe 657-8501, Japan. Correspondence and requests for materials should be addressed to M.A. (email: araki@port.kobe-u.ac.jp) or to T.H. (email: hasunuma@port.kobe-u.ac.jp)
} 